\title{
Notas sobre ideologia e educação
}

\section{Ari Fernando Maia ${ }^{1}$}

MAIA, A. F. Notes on ideology and education. Interface - Comunicação, Saúde, Educação, v. 2, n.3, 1998

The cornerstones for the critical theoretical assessment of educational reality have been the concept of ideology such as it was developed in Marxist literature, especially through the contributions of Gramsci, Lukacs and Althusser. The text seeks to investigate some of the consequences of the redevelopment of the concept of ideology put forth by T.W. Adorne and M. Horkheimer, with a view to attaining a critical reflection on the theme of education. The essay also highlights the ideological function of the cultural industry and of the growing technological orientation within broad segments of society, which directly influence school reality, as well as raising issues that have only rarely been considered to date.

KEY WORDS: ideology, historic-structural theory, education.

A base da elaboração teórica crítica da realidade educacional tem sido o conceito de ideologia como foi desenvolvido na literatura marxista, principalmente a partir das contribuições de Gramsci, Lukacs e Althusser. O texto procura explorar algumas conseqüências da reelaboração do conceito de ideologia, feita por T. W. Adorno e M. Horkheimer, para a reflexão crítica sobre o tema da educação, destacando a função ideológica da indústria cultural e do crescente processo de tecnificação em amplos setores da sociedade que influenciam diretamente a realidade escolar e colocam em pauta questões pouco exploradas.

PALAVRAS-CHAVE: ideologia; teoria histórico-estrutural; educação.

\footnotetext{
${ }^{1}$ Departamento de Psicologia da Faculdade de Ciências, Universidade Estadual Paulista - UNESP, Campus de Bauru.
} 


\footnotetext{
${ }^{2}$ Uma revisão importante do conceito, inclusive por conta de suas implicações explícitas para a escola, é o conceito de 'Aparelhos Ideológicos de Estado' elaborado por Althusser; as vicissitudes do conceito de ideologia na literatura marxista podem ser vislumbrados no artigo de Eagleton "A Ideologia e suas Vicissitudes no Marxismo Ocidental" (Zizek, 1997), em que o autor destaca ainda as

contribuições de Lukács e Gramsci.
}

A realidade escolar que vigora atualmente no Brasil, no bojo das 'modificações' econômico-sociais que ocorrem mundialmente e em acordo com elas, persiste sendo profundamente antidemocrática e excludente. A mera observação demonstra o que as pesquisas sérias, sem dúvida de forma mais eloqüente, comprovam: a escola brasileira não tem sido capaz de cumprir seu papel em uma sociedade desigual, qual seja, o de ir contra a corrente', resistir ao processo de progressivo fechamento das brechas que permitem fazer avançar o processo democrático, mantendo uma ordem social bárbara.

Para aqueles que se dispõem a pensar a escola nessa realidade, cumpre levar a sério a avaliação do contexto histórico e de suas vicissitudes com relação à educação. Não são poucos os autores, no âmbito da Psicologia, que se dispuseram e ainda se dispõem a pensar a realidade escolar de forma crítica. Sem dúvida, boa parte da produção científica em Psicologia Escolar procura desvendar criticamente as práticas educacionais em nosso país para apontar caminhos para ações democratizantes que permitam resistir à barbárie generalizada. Tentando acompanhar essa orientação, procurar-se-á pensar o fracasso da escola em resistir ao 'rolo compressor' neoliberal dentro da perspectiva teórica da Teoria Crítica, mais especificamente de um de seus representantes: Theodor W. Adorno.

O conceito adorniano que parece permitir uma articulação fértil para refletir sobre a realidade escolar é o conceito de Ideologia. O uso indiscriminado do termo ideologia, além do fato de vários autores 'marxistas' elaborarem o conceito de formas distintas ${ }^{2}$, impõe a necessidade de tecer algumas considerações a seu respeito, para identificar a posição adorniana.

Um dos aspectos irônicos da utilização atual, em alguns setores acadêmicos, no senso comum e na indústria cultural, do termo ideologia, é que se tenta negar o conceito e assim, ao mesmo tempo, ele é confirmado. Afirma-se que não há mais ideologias (!) para justificar a ordem social existente, e dessa forma, no plano da doxa, acaba-se por afirmar aquilo que, num certo sentido, no plano do pensamento filosófico-crítico, se reconhece como o conceito de ideologia. Segundo Adorno e Horkheimer (1978):

O cerne da justificação consiste na tentativa de afirmar o existente como o que é, como uma forma definitiva e não histórica, expurgando por decreto as contradições que, a despeito do que se diga, concretamente persistem. No entanto, cabe também não naturalizar essas contradições. Elas são fenômenos humanos e, portanto, fenômenos históricos decorrentes das formas sociais construídas pelos homens, implicando uma ação coletiva desses homens para ocorrer. Nesse sentido, a afirmação de que não há mais 
${ }^{3} \mathrm{O}$ artigo "A Ideologia", escrito por Adorno e Horkheimer (1978) foi publicado pela primeira vez em 1966.

${ }^{4} \mathrm{O}$ conceito de mediação é importante para a compreensão desse processo. Segundo Lalande (1993) o conceito de mediação indica a "ação de servir de intermediário entre um termo ou um ser do qual se parte, $e$ um termo ou um ser ao qual se chega, sendo esta ação produtora do segundo, ou pelo menos, condição de sua produção" (p. 656). ideologias quase diz a verdade, já que ela atualmente se confunde com a própria realidade social.

Numa avaliação que não identifique a noção de progresso simplesmente ao avanço técnico, mas principalmente ao progresso da humanidade reconciliada consigo mesma, as contradições que impulsionam esse processo parecem paralisadas. Portanto, a ideologia $e$ as teorias sobre ela estão sujeitas à dinâmica histórica cuja violência tentam justificar; $e$ as afirmações ideológicas não podem ser identificadas como simplesmente verdades ou mentiras.

$\mathrm{Na}$ época em que escreveram sobre esse conceito ${ }^{3}$, Adorno e Horkheimer viram-se diante de um contexto histórico em que pelo menos dois fatos eram cruciais: a regressão bárbara que ocorrera na Alemanha e a generalização da forma da indústria para praticamente todos os âmbitos da vida dos indivíduos. A atualidade da crítica dos filósofos pode ser vislumbrada na consideração de que as condições que possibilitaram o nazifascismo persistem enquanto avança ainda mais o processo de administração 'científica' da sociedade.

Quando as esferas da produção, distribuição e consumo das mercadorias obedecem a uma lógica industrial, a alienação do sujeito e a fantasmagoria do valor de troca que a caracteriza, materializada no equivalente universal, ocupa todos os espaços das relações entre os homens. Estes são constituídos como sujeitos pela mediação ${ }^{4}$ desta fantasmagoria administrada tecnicamente, o que constitui uma das faces da ideologia contemporânea segundo os autores: o véu tecnológico.

Nesse contexto, tornam-se problemáticas as relações entre a aparência $e$ a essência na sociedade, relações essas que servem de apoio para a crítica à ideologia, entendida como um conjunto "lógico, sistemático e coerente" (Chauí, 1994, p. 113) de idéias, crenças, valores, normas e leis que corresponderiam a uma má consciência da totalidade social em função de sua parcialidade - da 'autonomia' do espírito que não reconhece suas determinações -, relativa à classe social em que atua o sujeito ${ }^{5}$. A ideologia é entendida, assim, como um discurso lacunar, sofístico que, coerentemente com a realidade da posição social do sujeito, avessa, inverte a realidade social visando à manutenção do poder da classe dominante numa sociedade caracterizada pela luta de classes.

Atualmente, segundo Adorno (1994), o véu tecnológico, a administração totalitária da sociedade tolhe mesmo aquela autonomia irrefletida do espírito que caracterizava a ideologia:

\footnotetext{
A aparência poderia ser traduzida na formulação de que tudo que existe socialmente está, hoje, tão completamente mediatizado em si que exatamente o momento da mediação acaba sendo deformado por sua totalidade. Já não há lugar fora da engrenagem social a partir do qual se reconcilia na medida em que impõe pura $e$ simplesmente o caráter inconciliável do universal e do particular. Sua essência é a essência desnaturada; porém sua aparência, a mentira, graças à qual subsiste, é o lugar-tenente da verdade (p. 98).
} 
${ }^{5} \mathrm{~A}$ mesma autora (Chauí, 1997), em outra oportunidade define: "A ideologia, forma específica do imaginário social moderno, é a maneira necessária pela qual os agentes sociais representam para si mesmos o aparecer social, econômico e político, de tal sorte que essa aparência (...), por ser o modo imediato e abstrato de manifestação do processo histórico, é o ocultamento ou a dissimulação do real.

Fundamentalmente a ideologia é um corpo sistemático de representações e de normas que nos 'ensinam a conhecer e a agir. (...) o discurso ideológico é aquele que pretende coincidir com as coisas, anular a diferença entre o pensar, o dizer e o ser $e$, destarte, engendrar uma lógica da identificação que unifique pensamento, linguagem e a

realidade..." (p. 3). Essa definição tem elementos em comum com a posição adorniana, mas esta destaca o caráter totalitário da sociedade industrial moderna que acaba por identificar a ideologia como a imagem do existente; certamente aparência mas como que 'colada' à essência - o fazer histórico coletivo que caracteriza o modo de produção.
A crítica à ideologia é, necessariamente, uma crítica à própria sociedade $e$ ao processo de desenvolvimento do esclarecimento que mediou sua história, mas dado o caráter de falsidade do todo social (que anteriormente seria o critério da verdade), Adorno e Horkheimer (1978) atêm-se obstinadamente ao objeto particular para, por meio da determinação das mediações que o constituem, olhá-lo. A crítica à ideologia, portanto, é uma crítica imanente, isto é, a possibilidade de uma experiência 'não ideológica' implica considerar a singularidade do objeto em questão, assim como aquilo que nele representa o não singular, a cultura.

A posição dos indivíduos nesse contexto tornou-se delicada, pois quase nada resta da relativa autonomia de que dispuseram no início da ordem burguesa, e ao mesmo tempo, é pela ação conjunta desses 'indivíduos' que se reproduz o todo social. A ideologia, embora tenha origem na materialidade das relações sociais de produção, para garantir a reprodução dessas relações, toma corpo, 'ancora-se', no psiquismo individual, $e$ isso na medida mesma em que este é constituído pela mediação do 'todo falso'. Na sociedade, o fetichismo da mercadoria ampliado ad infinitum implica a desconsideração de toda particularidade - o primado do pensamento identificatório, da ratio técnica, que é irracional na medida em que é uma razão parcial, na medida em que desconsidera seus limites; o indivíduo constituído nessa sociedade impõe-se (com um 'pequeno auxílio' da Indústria Cultural) formas de pensar e de experienciar adequadas à ratio.

A justificação ideológica se dá na medida do não reconhecimento - ou do rechaço irado - daquilo que não é idêntico ao existente, ao preço, evidentemente, de uma violenta mutilação do não idêntico no próprio indivíduo. A falsa consciência se assenta sobre uma dinâmica de personalidade que dificulta ao sujeito a percepção $e$ a interpretação da realidade. Esta é interpretada a partir da projeção de elementos internos do sujeito sobre ela, $e$ isso tanto mais quanto mais rígida e estereotipada é a estrutura da personalidade. Dado que esta personalidade foi constituída pela mediação da cultura, ela será tanto mais rígida quanto mais excluir - como o faz o princípio lógico da sociedade capitalista - o não idêntico, e esta é a base 'psicológica' do preconceito, tão bem analisado por Adorno e seus colaboradores no estudo sobre a Personalidade Autoritária (Adorno et al, 1965).

No entanto, o próprio Adorno (1993) adverte contra algo que seria sumamente ideológico: pensar a sociedade como uma totalidade una, isto é, pensar como irremediavelmente conciliadas a sociedade e os indivíduos:

\footnotetext{
O mundo é o sistema do horror, mas quem ainda procura pensá-lo inteiramente como um sistema faz-lhe uma excessiva honraria, pois seu princípio unificador é a cisão, que reconcilia na medida em que impõe pura e simplesmente o caráter inconciliável do universal e do particular. Sua essência é a essência desnaturada; porém sua aparência, a mentira, graças à qual subsiste, é o lugar-tenente da verdade (p. 98).
} 

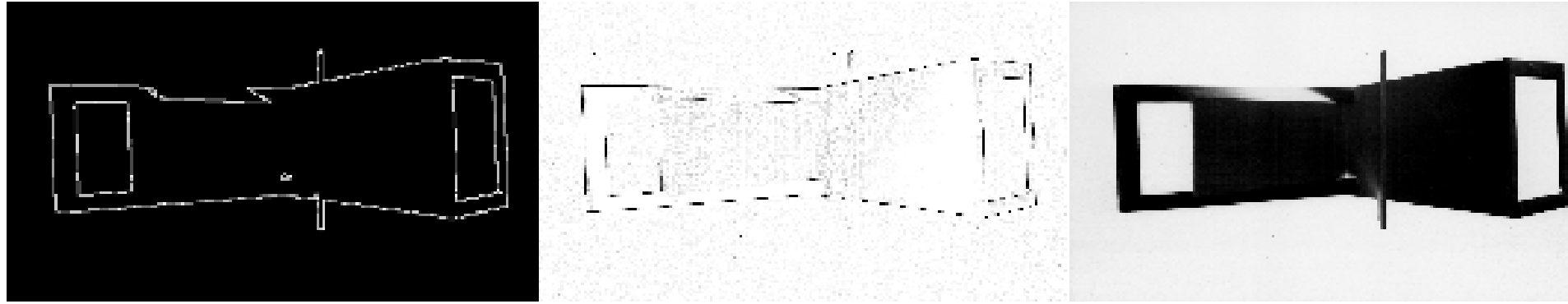

ESTUDO 1: FORMAS/FÔRMAS/CONSTRUÇÃO/CRIAÇÃO, Inácia Pereira, 1998

A falsa consciência diz respeito a determinado particular em questão e o falsifica em função de sua fixidez, em acordo com as fórmulas prévias dadas pela ordem social; a decifração da dinâmica da falsa consciência revela a violência da auto-submissão do sujeito a essas categorias prévias e seu ódio voltado contra a cultura que o submete. É verdade que essas formas de pensar e experienciar, dadas previamente, atendem a alguns impulsos dos sujeitos, particularmente aqueles ligados à pulsão de morte, mas isso não significa que alguma violência seja inevitável, mas somente que a forma atual de constituição do psiquismo dos indivíduos permite a gratificação da pulsão de morte por formas que os levam a ações que reproduzem a ordem social.

A indústria cultural é o principal veículo de divulgação e de manutenção dessa forma de ideologia e se aproveita dos impulsos ligados à pulsão de morte. O conceito de indústria cultural foi utilizado pela primeira vez na 'Dialética do Esclarecimento' (Adorno; Horkheimer, 1991), e identifica o conjunto dos meios de produção e divulgação da 'arte', isto é, de mercadorias 'culturais', no capitalismo moderno. Não pode ser confundida, portanto, com uma 'cultura de massas', como algo que emana naturalmente da população $e$ atende a seus gostos $e$ interesses. Ela funciona especificamente como força de unificação dos indivíduos $e$ força a falsa identidade entre os interesses da cultura e dos indivíduos, sendo o elemento fundamental da ideologia contemporânea.

A força de unificação da indústria cultural utiliza-se dos impulsos regressivos cuja demanda é pela mimese, pela imitação. Segundo Adorno (1993):

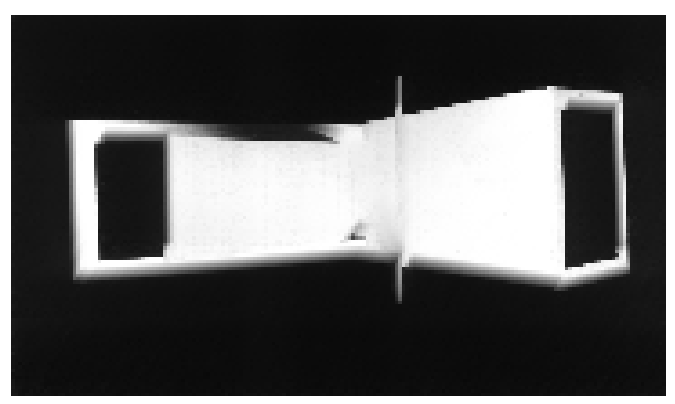

A indústria cultural modela-se pela regressão mimética, pela manipulação dos impulsos de imitação recalcados. Para isso ela se serve do método de antecipar a imitação dela mesma pelo espectador e de fazer aparecer como já subsistente o assentimento que ela pretende suscitar (p. 176).

Os produtos oferecidos têm como principal característica a padronização. O sempre igual é oferecido como se fosse diferente para dar a impressão de 
${ }^{6}$ Exemplos desse cinismo são abundantes. Quanto a um filme recente, alardeia-se seus custos de produção (os maiores de toda a história, segundo dizem) como se isso fosse algum critério para sua excelência. Numa matéria a esse respeito, no suplemento 'cultural' de um grande jornal, (O Estado de São Paulo, sábado, 16/01/98) a jornalista escreve, num tom francamente ameaçador, a frase que define o texto: 'Quem não vir o filme corre o risco de ficar sem assunto'. A ameaça de exclusão explícita representa a

verdadeira catástrofe que o filme reproduz com assustadora realidade. que são os sujeitos que 'escolhem', confundindo essa possibilidade de escolha entre mercadorias iguais com a 'individualidade'. A indústria cultural alardeia a si mesma como o âmbito do diferente, em que haveria possibilidade de escolha, mas está tão identificada ao processo produtivo industrial que suas mercadorias são tão fetichizadas quanto qualquer outra. A autopropaganda da indústria cultural é ameaçadora e cínica até os ossos, e acaba generalizando esse procedimento mentiroso fornecendo exemplos de como proceder aos sujeitos ${ }^{6}$.

A individuação procurada com relação a seus produtos esbarra na pseudo-individuação que os caracteriza. Nas palavras de Adorno (1994):
Por pseudo-individuação entendemos o envolvimento da produção cultural de massa com a auréola da livre escolha ou do mercado aberto, na base da própria estandardização. A estandardização de hits musicais mantém os usuários enquadrados, por assim dizer, escutando por eles. A pseudo-individuação, por sua vez, os mantém enquadrados, fazendo-os esquecer que o que eles escutam já é sempre escutado por eles, 'pré-digerido' (p. 123).

As possibilidades de o processo educativo se opor a esse estado de coisas implicam várias dificuldades. Segundo Adorno (1995a, p. 152): “A educação para a individualidade não pode ser postulada" pela circunstância de que não existem possibilidades sociais reais para o desenvolvimento de indivíduos. Mas, novamente, a questão não se resume à mera constatação:

\begin{abstract}
A situação é paradoxal. Uma educação sem indivíduos é opressiva, repressiva. Mas quando procuramos cultivar indivíduos da mesma maneira que cultivamos plantas que regamos com água, então isso tem algo de quimérico e de ideológico. A única possibilidade que existe é tornar tudo isso consciente na educação; por exemplo (...) colocar no lugar da mera adaptação uma concessão transparente a si mesma onde isto é inevitável, e em qualquer hipótese confrontar a consciência desleixada. Eu diria que hoje o indivíduo só sobrevive enquanto núcleo impulsionador da resistência (Adorno, 1995a, p. 154).
\end{abstract}

Além disso, retomando a questão da indústria cultural, os produtos oferecidos são ideológicos num outro sentido, pela forma técnica da transmissão das mensagens em alguns de seus veículos: a velocidade das seqüências de imagens na televisão e no cinema impossibilitam ao sujeito deixar de vê-las se quiser segui-las, e impedem o pensamento pela inexistência de tempo para elaborar as mensagens para além do mero reconhecimento e, além disso, habituam o sujeito a estímulos dessa natureza; a distinção de uma música popular com relação às outras músicas populares está em alguns detalhes, o que força novamente o reconhecimento como a única forma de apreensão.

É importante observar que a linguagem nesse meio torna-se racionalizada para o fim de transmitir mensagens ideológicas e, adaptada a 
esse fim, torna-se também tecnicamente controlada, tentando atribuir a cada palavra um sentido inequívoco. A identificação da palavra com a coisa, com o objeto que se quer significar, é uma forma de regressão mimética; o objeto é sempre algo mais que a palavra que o significa e além disso, a palavra pode ir além do objeto existente e projetar sua superação. A fixação e a padronização da linguagem é um dos efeitos nefastos da indústria cultural, pois nela a linguagem assemelha-se à propaganda: é simplesmente instrumento de manipulação e, como tal, perde sua relação com a verdade.

O empobrecimento da linguagem e das imagens veiculadas pela indústria cultural invadem o cotidiano escolar sob a forma de uma espécie de aversão à educação, de um querer se desvencilhar do "peso da experiência" (Adorno, 1995a, p. 150). Na verdade, os sujeitos rejeitam o que a eles foi reiteradamente negado: a possibilidade de uma experiência autêntica no contato com o objeto, o que evidentemente implica algum tipo de esforço $e$ de dedicação ao objeto, que o contato com as mercadorias da indústria cultural impossibilita.

Um outro dado importante com relação à indústria cultural é a ilusão de proximidade que é criada pelo encurtamento da distância entre os produtos oferecidos e o espectador, escondendo o fato de que um aparelho de televisão monopoliza a atenção de quantos espectadores estiverem diante dele, impedindo - ou pelo menos dificultando - a possibilidade de proximidade entre eles. A distância entre as imagens reais $e$ as imagens apresentadas pela televisão e pelo cinema - que são fragmentadas, editadas, dissolvidas - não é sentida como problemática pois a fragmentação é um complemento da dissolução das qualidades no mundo das mercadorias. Mas, é mais difícil de entender como os sujeitos se sujeitam à repetição dos quadros televisivos que, à primeira vista, deveriam causar desprazer.

A posição adorniana quanto a esse ponto demonstra sua desconfiança da afirmação simplória de que os conteúdos ideológicos são meramente 'inconscientes'. A ideologia contemporânea, na medida em que é mera afirmação do existente, é por demais visível. A não autonomia do espírito afirmada irrefletidamente também é ideológica, pois é o próprio sujeito que se envolve 'conscientemente' com os produtos oferecidos pela indústria cultural. Afirmar que a atuação dos sujeitos é puramente inconsciente ao falarmos de ideologia retira deles toda a responsabilidade sobre suas ações $e$ coloca a situação de um modo que anula toda a possibilidade de negatividade. Sobre essa questão, num texto sobre a música popular como manifestação da ideologia na indústria cultural, Adorno (1994) afirma:

\footnotetext{
Assim como a divergência entre a ilusão da propriedade privada e a realidade da propriedade pública é muito ampla (...) não se pode encarar tais ocorrências como sendo também totalmente inconscientes. Provavelmente é correto presumir que a maioria dos ouvintes, a fim de obedecer ao que eles encaram como desejos sociais e provar sua 'cidadania', juntam-se 'semi-humoristicamente' à conspiração (...) suprimindo a chegada à consciência do mecanismo operacional, mediante a insistência, diante de si e dos outros, no sentido de que a coisa toda, de qualquer modo, é apenas uma brincadeira bem limpa (p. 135).
} 

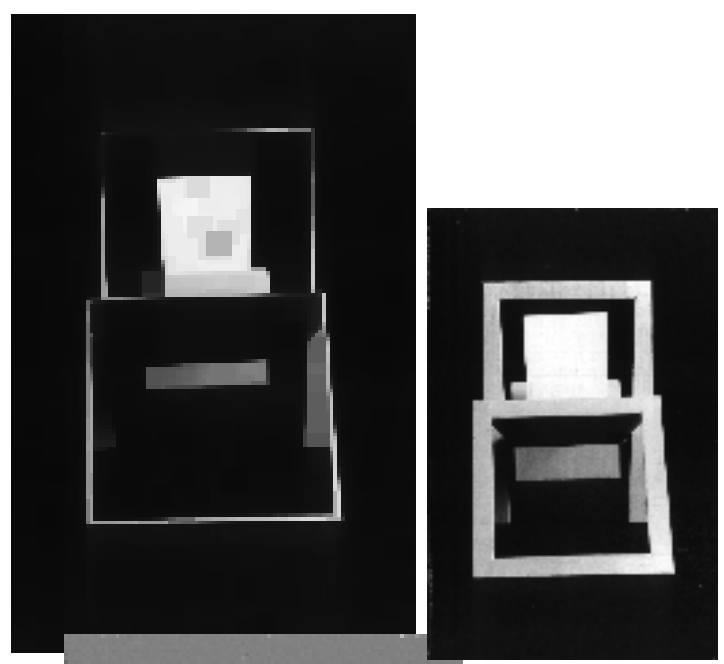

Mas, se é assim, vemo-nos diante de uma espécie de paradoxo: se os indivíduos precisam esforçar-se por não ver a natureza dos conteúdos ideológicos a que aderem, porque aderem? O 'véu' que se estende diante dos homens na sociedade 'falsa' é frágil, mas aparentemente indestrutível. Essa aparência pode ser ultrapassada pelo esforço do pensamento, da reflexão, mas isso implica tirá-los de sua paralisia induzida pela ordem social. Além disso, há a ameaça bem visível tanto da violência física quanto da exclusão e, em última instância, da dissolução do Eu. Mas a esperança consciente que resiste e representa a esperança de reconciliação está presente também no texto de Adorno e Horkheimer (1978), afirmando:

... no final das contas, a única coisa que se autonomizou foram as
relações entre os homens, soterradas sob as relações de produção.
Por isso é que a toda poderosa ordem das coisas continua a ser, ao
mesmo tempo, a sua própria ideologia, virtualmente impotente. Por
mais insuperável que seja o feitiço, é apenas feitiço (p. 203).

Considerando os apontamentos sobre o conceito de ideologia já feitos, poder-se-ia arriscar algumas observações sobre a educação escolar em nossas plagas. Obviamente não há pretensão de esgotar a questão, mas apenas de apontar alguns elementos para uma reflexão que é imprescindível. Em última instância, poder-se-ia pensar nos seguintes termos: em que medida e por que tipo de ações a escola - e também a produção 'científica' sobre ela - reproduzem a realidade social existente e, nesse sentido, reproduzem o mundo da alienação, da fetichização e da ideologia? Ou por outro lado, que tipo de ações possibilita 'ir contra a maré' e ao sujeito um pensar que não se reduza ao existente e que possa fazer avançar o processo educativo em direção à autonomia, ao desenvolvimento de qualidades no sujeito que permitam a ele o exercício da reflexão?

Em primeiro lugar, cumpre considerar a escola como um campo potencialmente fértil para contradições, refletindo a própria ordem social. Apontando algumas, pode-se citar, por exemplo: a necessidade ética de promover ações que levem à emancipação e à autonomia $e / o u$ à heteronomia e à adaptação vigentes; o predomínio de uma razão técnica $e$ identificatória levando à apropriação de determinado referencial técnico el ou a reflexão crítica, a razão emancipadora e o contato com o diferenciado.

Ao que parece, há uma contradição básica que diz respeito ao processo educativo; ele é, principalmente no capitalismo moderno, o principal meio de divulgação e ampliação do 'esclarecimento', do saber, portanto, de produção e reprodução da cultura, mas: "a civilização (...) origina e fortalece progressivamente o que é anticivilizatório (...) Se a barbárie encontra-se no próprio princípio civilizatório, então pretender se opor a isso tem algo de desesperador" (Adorno, 1995b, p.119-120). Referindo-se a Freud, nessa passagem Adorno aponta o cerne da questão: como se poderia interromper esse processo que, apesar de não ser inexorável, tem raízes tão profundas 
em nossa cultura? Entre o esclarecimento, a razão e a liberdade não há relação de vínculo natural ou automática. Por outro lado, não se pode abrir mão da razão se se aspira à liberdade.

A questão pode ser posta em outros termos: não há democracia sem emancipação, sem uma formação que permita aos sujeitos uma atuação crítica, política e ética em sua ação social. Nesse sentido, a emancipação pressupõe uma formação intelectual para toda a população, sem distinção quanto à futura tarefa social a ser cumprida pelo sujeito. Mas, além do fato de que esta formação não está em pauta, há uma outra, apontada por Adorno (1995a):

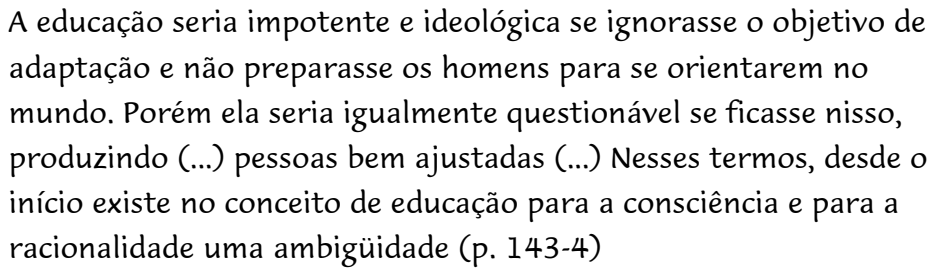

No entanto, o próprio filósofo adverte que, nas atuais condições, a necessidade de adaptação - já tão forçada em outras instâncias - torna-se secundária frente à necessidade de crítica. Em suas palavras: "A educação (...) teria nesse momento de conformismo onipresente muito mais a tarefa de fortalecer a resistência do que de fortalecer a adaptação" (Adorno, 1995a, p. 144).

Provavelmente, considerando a realidade escolar, encontrar-se-iam essas

atualmente

assumiu o lugar da verdade, do

'discurso

competente' como definido por Chauí (1997): "O

discurso

competente é aquele que pode ser proferido, ouvido e aceito como verdadeiro ou autorizado (...) porque perdeu os laços com o lugar e o tempo de sua origem" (p. 7). As raízes desse poder do discurso científico podem ser remetidas ao mito, que identifica a palavra $e$ a coisa, suma expressão ideológica - do poder e da impotência. contradições vivas, para além do simples 'ou ... ou ...'. Conformismo e resistência convivem no cotidiano escolar, mas é preciso também considerar que nem sempre o que representa resistência à violência imposta pela cultura através do processo educativo nega essa violência ou constitui uma experiência formativa; mais comum é a reprodução dessa violência, dos professores contra os alunos, destes contra os colegas mais fracos ou então o retorno da violência para o próprio sujeito.

A resistência é rompida na medida em que a ordem coletiva objetiva materializa-se em ações 'educativas' que se impõem violentamente ao individual abstrato, às singularidades. A observação empírica desse processo, sem dúvida difícil, é urgente e fundamental, e implica um olhar crítico às 'metodologias' que se pretendem educativas imbuídas de uma 'aura' de cientificidade técnica ${ }^{7}$. Certos conceitos adquiridos pelo saber 'pedagógico' pela incorporação de ciências como a Psicologia - como motivação, inteligência, os testes psicológicos etc, expressam sutilmente o princípio do equivalente. A exigência de ordem e disciplina aproxima a escola da indústria, embora seus fins sejam, ou devam ser, diversos. As ações intelectuais programadas obedecem aos moldes das ações braçais industriais -, pois são fragmentadas e sem sentido, destituindo o pensamento de sua dimensão de liberdade. Sobre a 'pedagogia', Adorno (1995a) afirma: 


\begin{abstract}
Max Scheler disse certa feita que só atuou pedagogicamente porque nunca tratou seus estudantes de maneira pedagógica. Se me permitem a observação pessoal, a minha própria experiência confirma inteiramente este ponto de vista. Ao que tudo indica, o êxito como docente acadêmico deve-se à ausência de qualquer estratégia para influenciar, à recusa em convencer (p. 104).
\end{abstract}

Essa é uma questão delicada: por um lado, não se pode abrir mão de estratégias pedagógicas - não necessariamente voltadas para o 'convencimento' - pois uma prática educativa sem intenção e reflexão pedagógicas seria cega; por outro, é preciso considerar que muitas das práticas pedagógicas atualmente utilizadas já são em si mesmas cegas $e$, além disso, é preciso sempre considerar que os problemas educacionais não podem ser resolvidos somente pedagogicamente; eles apontam para além da escola, para a sociedade. Novamente, a saída desse emaranhado parece ser a constante reflexão sobre as contradições que estão presentes no cotidiano escolar.

A tecnificação, principal face da ideologia, atinge o processo educativo de várias maneiras, decorrentes do desenvolvimento do processo educativo como um processo 'industrial'. Apenas para citar algumas; a) o conhecimento pode ser tratado como coisa em si, como dado técnico desprovido de outras mediações que não sua própria finalidade 'útil', e assim ser coisificado. Nesse caso a formação é substituída pela informação e pelo 'treino' dos alunos que, obviamente, aprendem mais que o mero conteúdo, incorporando a disciplina e a alienação. Por outro lado, cabe considerar que de fato alguns tipos de conhecimento - principalmente aqueles que 'não servem para nada', a Filosofia e a Arte, por exemplo, - têm um inegável valor humano, histórico e técnico (!) e, além disso, são os instrumentos de que se utiliza o pensamento crítico, sendo portanto imprescindível pensar a natureza dos conteúdos ensinados

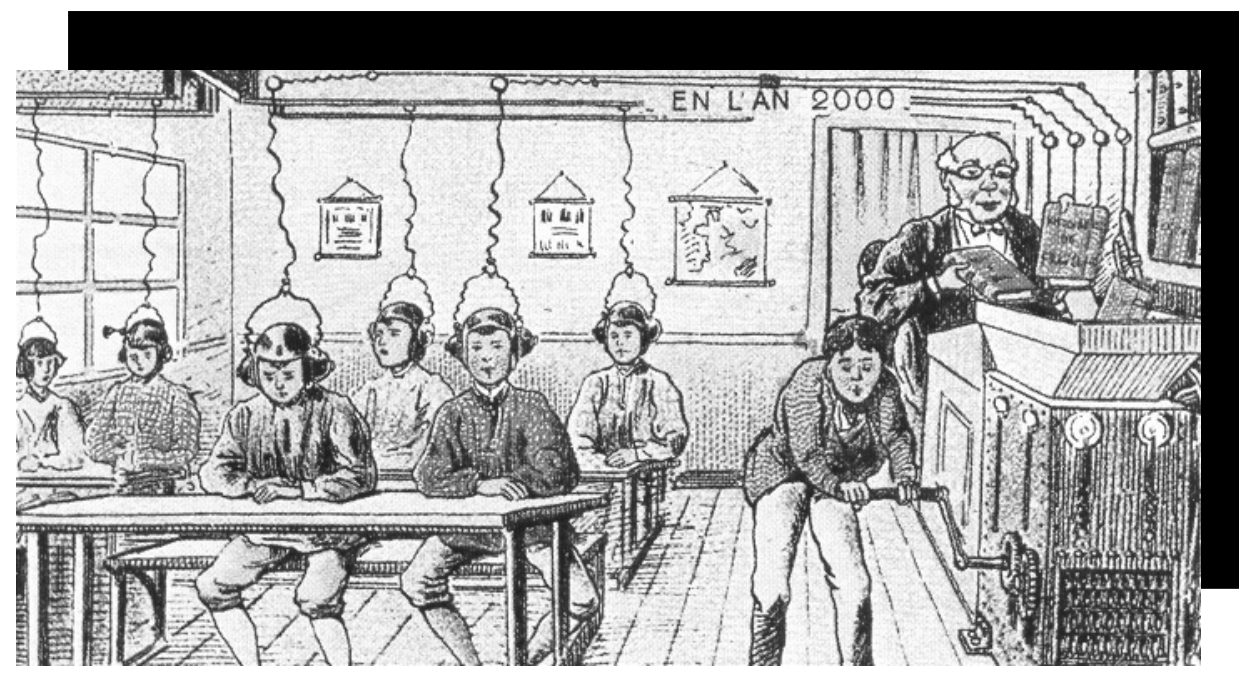
e o processo de aprendizagem individual dos alunos, para além do 'método' utilizado; b) o 'método' pedagógico pode ser um subterfúgio, um substituto à experiência no trato com os alunos; mas a experiência dos professores já é sempre - por assim dizer - mediada pela cultura e nesse sentido, todo cuidado é pouco, isto é, cabe ao professor uma constante capacidade de (auto) crítica e abertura à experiência. Ações que refletem preconceito vicejam no cotidiano escolar e somente uma constante reflexão - entendida como prática formativa também para o professor - pode minimizar esses 'reflexos' da realidade material na escola; c) a 'ciência' 
8 Uma excelente análise da generalização da forma industrial para a educação e dos desdobramentos dessa forma de ideologia para a propagação dos preconceitos encontra se no artigo "Aspectos que Permitem a Segregação na Escola Pública" (Crochik, 1997). psicológica, pedagógica, médica etc, também são incorporadas à prática do cotidiano escolar e em muitos casos se prestam à justificação da violência imposta aos alunos sob o disfarce do discurso competente. Estas ciências fornecem receitas e máximas à escola, técnicas sobre como proceder e lidar com os alunos. Mas uma 'técnica educativa' pronta e acabada seria, em última instância, uma espécie de 'sublimação' das máquinas de ensinar, à qual o professor deve se adequar para corresponder às expectativas de algum novo plano pedagógico governamental ou para corresponder à propaganda de determinada escola particular; d) são incorporados ao processo educativo meios técnicos novos, computadores, aparelhos de televisão etc, sem que se reflita sobre como essas novas técnicas influenciam o próprio processo educativo; e) são estimuladas a competição e a hierarquização entre os alunos, e seu desempenho é medido por instrumentos avaliatórios coisificados, como os testes psicológicos; f) institui-se o princípio do desempenho e da competência individual, tanto para alunos quanto para professores, e no bojo dessa ideologia, a capacidade $e$ a inteligência, por exemplo, são entendidas como características naturalmente individuais, desconsiderando sua dimensão social; como conseqüência, são instituídas classificações, baseadas em atributos arbitrários e subjetivos de competência, que servem, por exemplo, como critério para a criação de 'classes especiais', ou então outras distinções não oficiais, que afirmam a diferença daqueles que são discriminados para poder novamente confirmá-las - obviamente no sentido de mantê-las sob controle, $e$ assim permitem e estimulam o preconceito ${ }^{8}$.

Seria impossível imaginar todos os desdobramentos da tecnificação no âmbito escolar. No entanto, ter em vista essa realidade é fundamental para se poder resistir ao irresistível: ao fechamento das brechas de negatividade, à ideologia.

Em todos os casos em que a tecnificação e o 'discurso competente' são incorporados irrefletidamente, a finalidade do processo educativo - pelo menos as intenções apresentadas - e os meios para alcançá-la não são articulados. O próprio pensamento entendido como uma faculdade cognitiva, é ao mesmo tempo uma faculdade afetiva e ética (!), pois não há pensamento excluído das determinações inconscientes, que são estruturadas na prática dos indivíduos em sociedade constituindo sua personalidade, $e$ envolvendo uma totalidade afetivo-cognitiva. A exclusão da dimensão da práxis do processo educativo torna os processos cognitivos exigidos um simulacro do pensar, excluindo dele sua dimensão afetiva, ética e política. Por outro lado, seria idealismo imaginar que se pode simplesmente incorporar uma dimensão ético-política - a práxis - ao processo educativo se este está submetido ao processo social que o corrompeu. A crítica à ideologia consistiria na visão clara dessa exclusão, o 'cisco no olho que faz ver', a consideração das conseqüências de mais essa cisão em seus mais sutis desdobramentos.

É importante também observar que o saber produzido sobre a realidade educacional nem sempre atende à necessidade da crítica $e$, ao contrário, muitas vezes atende a necessidades ideológicas. No contexto histórico brasileiro há excelentes exemplos de como o conhecimento 'científico' sobre 
${ }^{9}$ Identificando os médicos pertencentes à Liga Brasileira de

Higiene Mental entidade criada por Gustavo Riedel em 1922, no Rio de Janeiro, que acumulou uma série de trabalhos sobre a realidade educacional brasileira. Alguns desses trabalhos como: "Idéas Geraes de Hygiene Mental" de F. Esposel, "Menores Incorrigiveis" de Ernani Lopes, "A Criança Problema" de Arthur Ramos, entre outros, são francamente protofascistas em algumas de suas proposições, por exemplo, a inferioridade racial $e$ a eugenia (Scwarcz, 1996). Mais tarde, a partir da década de 70 , a exclusão e o 'fracasso escolar' são atribuídos não mais à biologia, mas à carência cultural. De qualquer modo, em comum há a justificação da reprodução na escola das desigualdades sociais. a escola contribuiu para justificar a violência social e para implantar o ideal de uma sociedade administrada. Médicos higienistas e psicólogos escolares, ${ }^{9}$ por muito tempo cumpriram, obviamente com as melhores intenções, o papel de criadores de justificativas ideológicas para a realidade escolar nacional. Esse conhecimento sumamente ideológico é um exemplo eloqüente do iluminismo irrefletido. Além disso, nada garante que determinado saber não possa ser interpretado erroneamente e utilizado com finalidades que the são alheias. Reconstituir a possibilidade da experiência e da crítica é urgente e fundamental a todos os envolvidos no processo educativo.

A possibilidade de ações que levem à formação (Bildung) no sentido em que o termo é utilizado por Adorno implica uma crítica permanente, uma reflexão que ultrapasse o existente, reconhecendo as determinações objetivas por ele constituídas. Nesse sentido, pensar a formação implica pensar a exclusão e a violência em todas as suas nuances, especialmente a exclusão do singular, do diferenciado, que pode se dar sem que os alunos deixem de freqüentar as aulas e, o que é pior, sob a aparência de perfeita ordem e ótima produtividade. Nesses casos, teremos profissionais respeitados, aparentemente competentes, mas envolvidos com a reprodução da barbárie que viceja ao nosso redor, e que depende de nós para persistir ou sucumbir.

\section{Referências bibliográficas}

ADORNO, T. W. et al. La personalidad autoritária. Buenos Aires: Ed. Proyección, 1965.

ADORNO, T.W. Mínima moralia. São Paulo: Ática, 1993. Sobre música popular. In: COHN, G. Theodor Adorno. São

Paulo: Ed. Ática, 1994. Educação e emancipação. Rio de Janeiro: Paz e Terra, 1995a. Palavras e sinais: modelos críticos 2. Petrópolis: Vozes,

1995b.

ADORNO, T. W; HORKHEIMER, M. Dialética do esclarecimento. Rio de Janeiro: Zahar Editor, 1991.

Buenos Aires: Ed. Proteo, 1978.

CHAUI, M. S. O que é ideologia. São Paulo: Brasiliense, 1994. Cultura e democracia. São Paulo: Cortez, 1997.

CROCHIK, J. L. Aspectos que permitem a segregação na escola pública. In: Educação Especial em Debate. São Paulo: Casa do Psicólogo, CRP 06, 1997.

LALANDE, A. Vocabulário técnico e crítico da filosofia. São Paulo: Ed. Martins Fontes, 1993.

SCWARCZ, L. M. O espetáculo das raças. São Paulo: Companhia das Letras, 1996.

ZIZEK, S. Um mapa da ideologia. Rio de Janeiro: Contraponto, 1996. 